\title{
PTEN Deficiency
}

National Cancer Institute

\section{Source}

National Cancer Institute. PTEN Deficiency. NCI Thesaurus. Code C153467.

A condition of decreased or absent presence or activity of phosphatidylinositol 3,4,5trisphosphate 3-phosphatase and dual-specificity protein phosphatase PTEN, which is associated with multiple hamartoma syndrome (Cowden syndrome) and increased risk for development of several types of malignant cancers, including head and neck, breast, lung and prostate cancer and g lioblastoma. 